\title{
Pain and Suffering: The Reality of Being Positive with HIV/AIDS
}

\author{
Retno Lestari ${ }^{1}$, Wenny Nugrahati Carsita ${ }^{2}$ \\ ${ }^{1}$ Department of Nursing, University of Brawijaya, Indonesia \\ ${ }^{2}$ Department of Nursing, Stikes Indramayu, Indonesia
}

\begin{tabular}{|c|c|}
\hline Article Info & ABSTRACT \\
\hline Article history: & HIV/AIDS remains a global health problem and affects the overall quality of \\
\hline Received Sen 102016 & life. People living with HIV/AIDS are at risk for developing mental health \\
\hline Kecerved sep iv, 2010 & problems, such as depression and anxiety. This condition can fuel additional \\
\hline Revised Oct 20, 2016 & problems, such as non-compliance in taking HIV medications. This study \\
\hline Accepted Nov 6, 2016 & $\begin{array}{l}\text { aimed to explore the meaning in life whileliving with HIV/AIDS among } \\
\text { people in West Java.This study used an interpretive phenomenological }\end{array}$ \\
\hline Keyword: & $\begin{array}{l}\text { approach. Data were collected by in-depth interviews among } 7 \text { participants } \\
\text { who experienced HIV-positive. The results were analyzed by Van Manen }\end{array}$ \\
\hline HIV/AIDS & method. Four themes were identified in this study: (1) experiencing mental \\
\hline Pain & suffering, (2) be free from mental suffering, (3) trust the HIV/AIDS \\
\hline Phenomenology & $\begin{array}{l}\text { S not contagious and there is a hope to live and (4) performing activities to } \\
\text { improve the quality of life. Participantsfeels that living with HIV/AIDS is not }\end{array}$ \\
\hline Suffering & $\begin{array}{l}\text { easy. They suffered from fear and anxiety, on the other hand it emerged as a } \\
\text { hope and decision to seek support, treatment, and performing activities to } \\
\text { improve the quality of life. }\end{array}$ \\
\hline
\end{tabular}

Copyright () 2016 Institute of Advanced Engineering and Science. All rights reserved.

\section{Corresponding Author:}

Retno Lestari,

Department of Nursing,

University of Brawijaya,

Jl. Veteran-Malang, Jawa Timur-65145, Indonesia.

Email: retno.lestari98@gmail.com

\section{INTRODUCTION}

HIV/AIDS is one of the biggest problems around the world. People living with HIV/AIDS (PLWHA) experience both physical and psychological difficulties.They struggle with daily problems such as stigma, financial difficulties, abuse, and other mental pain which can affect their quality of life.They feel worried, depressed or irritated [1]. Prolonged mental health problems has an effect on poor quality of life.

PLWHA often faced with complex conditions whether to reveal or hide the condition. Hiding the disease can result in psychosocial problems because of the burden in keeping the secret [2]. On the other hand, disclosing their conditions make them scared and worried with people thinking. As a fact, people often have negative views about HIV/AIDS [1].

Fear influence PLWHA for delaying or avoiding treatment and adherence to treatment. They feel that they were not eligible to receive treatment and this condition may reduce their motivation to go to comunity health center [3-4]. This condition can worsen their health status and may hasten death.

HIV prevalence in West Java around 451 cases in 2012. Based on these cases, health care center provide several programs which give opportunities for PLWHA to express their feelings, check their physical conditions and provide facilities for diagnostic laboratorium. Health care providers feel that discussing about HIV/AIDS is still a taboo topic in this society. Public misconceptions about HIV/AIDS which this disease are associated with behaviours that some people disapprove of, such as being sex workers, homosexuality 
and etc. Therefore, this study aimed to explore the meaning in life while living with HIV/AIDS among people in West Java.

\section{RESEARCH METHOD}

This interpretive phenomenology study used in-depth semi-structured one-on-one interviews to explore the meaning in life while living with HIV/AIDS among people in West Java.Seven participants were eligible to participate if they: HIV-positive and showed interest tosharetheir experiences in details.

A snowball sampling was used for recruiting participants from community integrated health center (Puskesmas). Recruitment flyers were placed on boards at Puskesmas. Participants were contacted by phone and researchers arranged for home visit if they agreed to participate in the study. As the topic of this study was very sensitive, participants could be reluctant to talk about their experiences. The researcher used personal contacts and social network through health care providers to reach participants.

Consent was signed after each participant had explanations about the study purpose. Recruitment of participants still continued untildata saturated was achieved.Ethical approval was gained from the Health Polytechnic Malang, Ministry of Health of Republic of Indonesia Review Board, April 2016 (Reg.No.: 077 / KEPK / -POLKESMA / 2016). Written approval from the site was also obtained.

Data were collected between May and July 2016. Participants were interviewed in West Javanese language at their homes by researcher who is fluent in the language. Prior to interview, consent was obtained after the researchers explained about the research and procedures. They were informed they could withdraw from the study at any time. The open-ended interview guide was developed by the authors. Interviews lasted 100 to 120 minutes, were digitally audio recorded and transcribed verbatim in West Javanese Language. The questions guide used are presented to let participants express themselves freely in their own words:

1. Can you tell me at the first time, how do you feel when you now that you were HIV positive?;

2. What were you feeling at that time?

3. Do you know what is HIV/AIDS at that time?

4. What was going through your mind before knowing the diagnosis?

5. How did you break the news to other people, such as your family?

6. Can you describe how the person reacted to the news?

7. What did you feel after that?

8. What went through your mind after that?

9. How did it feel if you did not tell anyone about your status?

10. What was going through your mind when you chose not to tell anyone about your status?

11. What meaning does your experience have for you?

Participants ranged in age from 25 to 44 years, more than $70 \%$ were female. One was single and six were married. Six of the women were employed and one was unemployed. Five participants had an elementary education, one was graduated from high school and one participant never had a formal education.

Data were analyzed using Van Manen's (1990) hermeneutic phenomenological method within the following threeprocesses: (1) the holistic, (2) the selective and (3) the detailed process.In the holistic process, research captured the meanings of the whole text. In the selective step, essential phrases were pulled out as the keywords. In the detailed process, all data were analysed until all themes were identified [5].

Trustworthiness in qualitative study refers to validity and reliability. Validity means the accuracy of the idea in the transcripts reflects what actually happened. Reliability means that the study results would also be obtained if different researchers repeated the study. Credibility is one of the most important indicators for establishing trustworthiness. To ensure the credibility of research findings, researchers repeated contact with participants andpeer debriefing (allowing time for feedback and discussion of participants feelings) regarding the data collected, analysis and interpretation [6]. In this study reflexivity was ensured by writing notes in portofolio which consisted of experiences throughout thestudy process. Investigator triangulation used in this study during data interpretation.

\section{RESULTS AND ANALYSIS}

\subsection{Experiencing mental suffering}

Participants express HIV/AIDS as a suffering process, it is an unpleasant feeling. This theme extracted from several sub- themes: feeling uneasy, feeling sorrow, feeling awful, feeling helpless and depressed, denying my conditions. Uneasy feeling expressed by the participants as fear. The fear was expressed as a fear of transmitting disease, worried with their conditions and death; feeling worried about people judgments. One of the thoughts experienced by PLWHA comes from fear with people judgments when disclosing the condition [7]. It was expressed by participant's statement: 
"The first to know so he said that if stuck contagious, is not the first time I was also afraid of myself, afraid of transmitting" (Demi). "O God! I have a disease like this, I was going to die, just let me alone" (Kadi).

Fear is a feeling induced by a perceived of danger, feelings which participants described as a fear of their own death. Knowing that they were positive with HIV/AIDS was very painful, they were worried with their own conditions, their job and the loss of their life.

Another sub themes are feelingsorrow, it is a feeling of sadness, it is a sad condition. It wasstated by participant's statement:"When I knew the first time that i got HIV, i was feel sad, definitely sad"(Puna).

Feeling awful, helpless and depressed were stated by participants, as they thought it could not happened: "At first, i just feel awful, i feel ashamed with myself" (Demi). "It feels like..it is the end of the world, just..just can not be treated, it is all over" (Tuba).

PLWHA feel depressed by the conditions as they thought that their life has ended. Depression can make HIV disease progress faster as PLWHA often refused to get treatment and they think that this disease can not be treated.

Denying the conditions was another feeling which expressed by participants: "I feel angry, I just can not believe the diagnosis" (Nima). Denial expressed as the first emotional response when PLWHA knew about being HIV positive. Being denial in too long could prevent participants from taking better movements. Therefore, health professionals should give their support to motivate PLWHA to accept their condition.

PLWA might feel alone, fear of death and depressed at times. Mood changes, particularly depression commonly happened in individuals with HIV/AIDS, and its prevalence was significantly higher among PLWHA [8]. Depression couldinterfere with HIV treatment and often under diagnosed. Depression is a significant predictor of non compliance to medication treatment [9]. Therefore, depression and other psychological issues should be treated by health care professionals.

\subsection{Be free from mental suffering}

Participants also hope that they want to be free from this suffering process. They wanted to live like normal people. This theme was developed by two sub-themes: wanted to be free from mental and physical problems; and hoped for social support. It was expressed by the statements:

"I hope that i can live like normal people, healthy as usual" (Tuba).

"I still want to live, I want to look after my kids" (Kaya).

"I wanted to get better, I wanted to check my conditions and get the treatment" (Kaya).

Positive expectations are important component in the treatment of HIV/AIDS. Hope can be a powerful strengthfor people living with HIV. It can encourage them to plan for the treatment [10].

\subsection{Trust the HIV/AIDS disease is not contagious and there is a hopeto live}

Participants believed that HIV/AIDS is not contagious as doctor and nurses told to them that they do not have to be afraid about the disease.PLWHA stated that after knowing the condition of the disease, they expect to receive medical assistance, information about the disease and emotional support [10]. Participants felt that encouraging a positive aspect about HIV/AIDS disease could create a certain mind-set to maintaining their hope level.This theme was developed from sub-themes: trust HIV/AIDS is not contagious and there is a hope to live. It was expressed by the statements:

"ummmm...yes, $\mathrm{i}$ know that this disease is not contagious, doctor told me like that" (Demi).

"Please..please sit here, next to me, I told everyone to do so, i am ok, you will be fine withme" (Tuba).

After participants received adequate information regarding HIV/AID and motivation fromcompetent health care professionals, they understand that there is a possibility of a better future and hope [11]. In fact, AIDS-NGO professionals offered severalservices for PLWHAto perform activities at groups of socially vulnerable individuals to reduce stigma of being positive with HIV/AIDS. These activities of AIDS-NGOs are based on daily basic needs which focused on empowerment, knowledge and skills. The aim of these activities was to improve the health status, quality of life and drug compliance [12]. However, these activities require great effort and dedication from health care professionals to maintain and evaluate them. PLWHA encouraged that their help include about legal assistance, employment and health care [13].

\subsection{Performing activities to improve the quality of life}

Performing activities among PLWHA can improve their health status. Health professionals also motivated participants to check their condition at community integrated health center. The statements expressed as follows:

"yes, they told me to come to the health center each week, so i have to go there" (Tuba). 
"I just want to be healthy, so I have to go to there, I have to be checked, I would not give up with this condition" (Kaya).

There is also volunteers which also PLWHA in community that support these participants to get a better life, this was stated by:"I do, I help other people with HIV, so they know that they are not alone, I do have HIV, you see, I am alright” (Kaya)."I helped my friend and suggest them to get medications...." (Buna).

There were high levels of stigma and discrimination towards PLWHA which leads to the feelings of fear and suffering. Participants in this study believed that maintaining daily activities could promote their mental and physical well-being. Previous study explored that daily routine activities can transform PLWHA life [14]. PLWHA has been motivated by health professionals to go to the health center for treatment. It was revealed that the supports given by health workers strongly influence their decisions and actions of PLWHA to disclose their condition and gain appropriate treatment.Self-disclosure helps people living with HIV receive emotional support, access to treatment and care [15]. In facilitating disclosure, a counsellor or health care professionals should understand about their mental health condition and also provides information, support regarding HIV/AIDS treatment [16].

Accepting their conditions, maintaining their lives with HIV andseeking the acceptance of their families and friends helps them to be pro-active and choosing to live better. The study showed that HIVpositive people find a relief after revealing their condition. Providing emotional support can help people living with HIV receive their conditions, reduced feelings of fear and isolated from society.

\section{CONCLUSION}

People living with HIV/AIDShave several mental health problems, such as depression and anxietyUnderstanding the experience among people with HIV is important to guide actions in the health practice to support them during their suffering stage. Health care professionals have to expand their role to motivate these patients for a better quality of life.

The results were identified in this study, people living with HIV have experiencees in mental suffering, and however they wanted to be free from mental suffering. These people trust the HIV/AIDS disease is not contagious and there is a hope for them to live and performing activities to improve the quality of life. The process of revealing HIV/AIDS conditions allowed us to describe better understanding of the phenomenon especially in light of deliberate public misconceptions about HIV/AIDS disease.

\section{ACKNOWLEDGEMENTS}

We would like to express our special thanks to all of the participants for sharing their experiences. We also received support from Community Integrated Health Center, School of Health Sciences in Indramayu and School of Nursing in Faculty of Medicine, Brawijaya University.

\section{REFERENCES}

[1] S. R. Chaudoir, et al., "Understanding HIV disclosure: A review and application of the sisclosure processes model," Social Science \& Medicine, vol/issue: 72(10), pp. 1618-1629, 2011.

[2] G. Rouleau, et al., "Disclosure experience in a convenience sample of quebec-born women living with HIV: A phenomenological study," BMC Women's Health, vol/issue: 12(37), pp. 1-11, 2012.

[3] S. E. Stutterheim, et al., "Disclosure of HIV status to health care providers in the Netherlands: A qualitative study," Journal of the Association of Nurses in AIDS Care, vol/issue: 27(4), pp. 485-494, 2016.

[4] J. D. P. Bird and D. R. Voisin, "You're an open target to be abused": A qualitative study of stigma and HIV selfdisclosure among black men who have sex with men," American Journal of Public Health, vol/issue: 103(12), pp. 2193-2199, 2013.

[5] D. F. Polit and C. T. Beck, "Nursing Research: Generating and Assessing Evidence for Nursing Practice," Ninth edition, Lippincott Willian \& Wilkins. Philadelphia, pp. 152-522, 2012.

[6] S. G. Jeanfreau and L. Jack, "Appraising Qualitative Research in Health Education: Guidelines for Public Health Educators," Health Promot Prac, vol/issue: 11(5), pp. 612-617, 2010.

[7] A. E. Arrey, et al., "It's my secret": Fear of disclosure among Sub-Saharan African migrant women living with HIV/ AIDS in Belgium," PLOS ONE, vol/issue: 10(3), pp. 1-22, 2015.

[8] J. S. Merlin, et al., "Two Pains Together:Patient Perspectives onPsychological Aspects of Chronic Pain while Living with HIV," PLoS ONE, vol/issue: 9(11), pp. e111765, 2014.

[9] R. Kant, "A Comparative Study of Phenomenology of Depressionbetween The HIV Positve Patients Attending HIV Clinic and The Patients Attending Psychiatry OPD," Global Journal for Research Analysis, vol/issue: 3(6), pp. 155-156, 2014.

[10] S. Yadav, "Perceived social support, hope, and quality of life of persons living with HIV/AIDS: A case study from Nepal," Qual Life Res., vol/issue: 19(2), pp. 157-66, 2010. 
[11] J. R. Cutcliffe and K. Zinck, "Hope Maintenance in People LivingLong-term with HIV/AIDS," Qualitative Research Journal, vol/issue: 11(1), pp. 34-49, 2011.

[12] A. Berenguera, et al., "Experiences about HIV-AIDS preventive-control activities. Discourses from nongovernmental organizations professionals and users," Scielo Public Health, vol/issue: 25(3), 2011.

[13] A. Berenguera, et al., "Core indicators evaluation of effectiveness of HIV-AIDS preventive-control programmes carried out by nongovernmental organizations. A mixed method study," BMC Health Services Research, vol. 11, pp. 176, 2011

[14] Y. R. Zhou, "The phenomenology of time: Lived experiences of peoplewith HIV/AIDS in China," Health, vol/issue: 14(3), pp. 310-325, 2010.

[15] G. Yonah, et al., "HIV serostatus disclosure among people living with HIV/AIDS in Mwanza, Tanzania," AIDS Research and Therapy, vol/issue: 11(5), pp. 1-5, 2014.

[16] M. M. Walcott, et al., "Facilitating HIV status disclosure for pregnant women and partners in rural Kenya: a qualitative study," BMC Public Health, vol. 13, pp. 1115, 2013.

\section{BIOGRAPHIES OF AUTHORS}

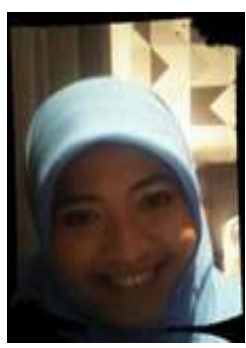

Retno Lestari is a lecturer in School of Nursing, Faculty of Medicine, University of Brawijaya. Her specialty is in mental health nursing. She received her bachelor of nursing in Nursing Faculty, University of Indonesia. Her master of nursing was achieved from Monash University, Australia. She also teaches qualitative research methodology. Her publications on 2013, "Caregivers strategies in managing aggressive in dementia clients", which is sold online, motivated her to do more qualitative research in nursing. She believes that qualitative research is relevant to be implemented in nursing field.

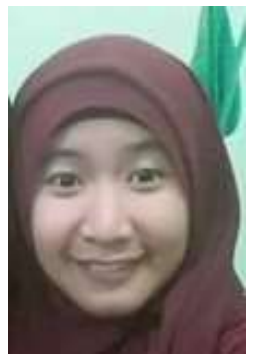

Wenny Nugrahati Carsita is a lecturer in School of Health Sciences in Indramayu. Her specialty is in mental health nursing. She received her bachelor of nursing in the school where she works at the moment. Her master of nursing was achieved from School of Nursing, Faculty of Medicine, University of Brawijaya. She took her master specialty in mental health nursing. She has several awards from her bachelor and her master as high distinction student. 